\title{
Educação de jovens e adultos, matemática e ensino remoto
}

\author{
Youth and adult education, mathematics and remote education
}

Educación de jóvenes y adultos, matemáticas y enseñanza remota

\author{
Luciene Lima de Assis Pires ${ }^{1}$ \\ (1D [0000-0002-0187-3749] \\ Paulo Henrique de Souza ${ }^{2}$ \\ (1D [0000001-9269-5126] \\ Nilton Lásaro Jesuíno 3 \\ iD [0000-0001-8683-7765]
}

\section{Resumo}

A educação de jovens e adultos (EJA) é uma modalidade de ensino que traz consigo histórias e lutas de educandos repletas de detalhes, anseios, apreensões, esperanças. Estas histórias e lutas, em 2020, foram entrecortadas por uma pandemia que acrescentou aos educandos outras preocupações. Este artigo retrata este debate e salienta como o processo ensino-aprendizagem na EJA se efetivou no Brasil em meio aos desafios postos para aulas não presenciais. Apresenta-se aqui um recorte de uma pesquisa desenvolvida em cinco municípios no estado de Goiás no ano de 2020. No caso refere-se ao acompanhamento de uma educanda EJA em uma escola pública federal, no município de Jataí-GO. O acompanhamento realizou-se na disciplina de Matemática, iniciou-se com entrevista presencial, no mês de fevereiro, antes do início da pandemia. Com a suspensão das atividades presenciais na escola, a pesquisa foi redimensionada e, além do acompanhamento da educanda na disciplina, optou-se por verificar também as dificuldades referentes ao ensino remoto. Desenvolveu-se pesquisa qualitativa. A coleta de dados se deu por meio de um questionário com perguntas estruturadas e entrevistas com perguntas semiestruturadas, em um primeiro momento presencial e depois por celular. Todas as entrevistas foram gravadas e depois transcritas. Observou-se que as dificuldades dos educandos em Matemática foram potencializadas pelo ensino remoto. Verificou-se que na escola pesquisada os alunos tiveram auxílio financeiro para subsidiar o acesso à internet e empréstimo de equipamentos para o uso e acesso às aulas remotas, o que foi fundamental para a aprendizagem da educanda pesquisada.

Palavras-chave: Educação de jovens e adultos. Educação Matemática. Ensino remoto.

\section{Abstract}

Youth and adult education (EJA) is a teaching method that brings stories and struggles of students full of details, desires apprehensions, hopes. These stories and struggles, in 2020, were interrupted by a pandemic that added other concerns to students. This article presents this debate and emphasize how the teaching-learning process at EJA took place in Brazil amid the challenges posed for non-classroom classes. It's shown here part from a research developed in five municipalities in the state of Goiás in

${ }^{1}$ lucieneapires@gmail.com, Doutora em Educação, professora, Instituto Federal de Educação e Tecnologia de Goiás, Jataí/Goiás/Brasil.

2 phsouzas@gmail.com, Doutor em Física, professor, Instituto Federal de Educação e Tecnologia de Goiás, Jataí/Goiás/Brasil.

3 niltonlas@gmail.com, Especialista em Matemática Aplicada, professor, mestrando, Instituto Federal de Educação e Tecnologia de Goiás, Jataí/Goiás/Brasil. 
2020. In this case, it refers to the monitoring of an EJA student in a federal public school in Jataí-GO. The follow up was made in the Mathematics discipline, started with an interview, in February, before the start of the pandemic. With the suspension of the classroom activities, the research was redimensioned and, in addition to monitoring the student in the discipline, it was decided to also check the difficulties related to remote teaching. Qualitative research was developed. The data collection was made through a questionnaire with structured questions and interviews with semi-structured questions, firstly in person and then by phone. All interviews were recorded and then transcribed. It was observed that the difficulties of students in Mathematics were enhanced by remote education. Also observed that in the researched school students had financial assistance to subsidize access to the internet and loan equipments for use and access to remote classes, which was fundamental for the learning of the researched student.

Keywords: Youth and adult education. Mathematics Education. Remote teaching.

\section{Resumen}

La Educación de Jóvenes y adultos (EJA) es una modalidad de enseñanza que trae historias y luchas de estudiantes llenas de detalles, deseos, aprensiones, esperanzas. Esas historias y luchas, en 2020, fueron interrumpidas por una pandemia que agregó otras preocupaciones a los estudiantes. Este artículo retrata ese debate y destaca cómo el proceso de enseñanza-aprendizaje, en EJA, se llevó a cabo en Brasil en medio de los desafíos planteados para las clases no presenciales. A continuación, se muestra un extracto de una investigación realizada en cinco municipios del estado de Goiás en el año 2020. En ese caso, se refiere al acompañamiento de una alumna de EJA en una escuela pública federal, en el municipio de Jataí-GO. El acompañamiento se realizó en la disciplina de Matemáticas, se inició con una entrevista presencial, en febrero, antes del inicio de la pandemia. Con la suspensión de las actividades presenciales en la escuela, se redimensionó la investigación y, además de monitorear la alumna en la disciplina, se decidió verificar también las dificultades relacionadas con la enseñanza a distancia. Se desarrolló una investigación cualitativa. La recolección de datos se realizó por medio de un cuestionario con preguntas estructuradas y entrevistas con preguntas semiestructuradas, primero presencial y luego por teléfono móvil. Todas las entrevistas fueron grabadas y luego transcritas. Se observó que las dificultades de los estudiantes en Matemáticas se vieron reforzadas por la educación a distancia. Se encontró que en la escuela encuestada, los estudiantes contaban con ayudas económicas para subsidiar el acceso a la internet y préstamo de equipos para uso y acceso a las clases remotas, lo cual fue fundamental para el aprendizaje de la estudiante investigada.

Palabras clave: Educación de jóvenes y adultos. Educación Matemática. Enseñanza remota.

\section{Considerações iniciais}

A Educação Matemática é objeto de análise há várias décadas. Diferentes estudos e pesquisas envolvem os níveis e as modalidades de ensino tendo como objeto o processo ensino-aprendizagem, as tecnologias digitais, dificuldades de aprendizagem, metodologias de ensino, dentre outros. Pode se considerar que a Educação Matemática é universal. Segundo D’Ambrósio (1993, p. 15) “reflexões, teorias e estudos sobre Educação Matemática vêm desde a Antiguidade". Para ele,

A grande expansão da educação a partir do final do século passado e que se manifesta com maior intensidade nos países menos desenvolvidos a partir de meados deste século, leva à universalização da Educação Matemática. Universalização no sentido pleno: ensinar Matemática para todos e, 
praticamente, a mesma Matemática em todo o mundo. (D’AMBRÓsıO, 1993, p. 12).

Analisando pesquisas sobre o ensino, Maffei e Silva (2018) analisam "como a comunidade brasileira de pesquisadores em Educação Matemática tem discutido e abordado os aspectos subjetivos da/na relação com esta área do conhecimento" (MAFFEI e SILVA, 2018, p. 440). Na pesquisa realizada, esses autores verificaram que os pesquisadores analisam aspectos subjetivos na constituição do educador e de sua identidade,

E nos vínculos que as pessoas estabelecem com a Matemática, que incluem atitudes, crenças, concepções, percepções, e tem reconhecido a importância de tais aspectos como constitutivos não só do sujeito [...], mas da profissão professor que ao lidar com diferentes sujeitos naturalmente se faz atravessar e atravessa por subjetividades. (MAFFEI; SILVA, 2018, p. 451).

Pesquisas sobre a Educação Matemática e a Educação de Jovens e Adultos (EJA) também ganharam destaque nos últimos anos visto haver nesta modalidade de ensino dificuldades dos educandos em relação à Matemática. Segundo Oliveira (2013),

Analisando as escritas de diversos autores, observa-se que uma das dificuldades no ensino da matemática na EJA, é a forma de desenvolver junto aos educandos a matemática com sua resolução científica, pois os educandos sabem fazer as resoluções matemáticas da maneira que aprenderam no seu dia a dia. (OLIVEIRA, 2013, p. 10).

Em estudos sobre o estado da arte das teses e dissertações relacionando Educação Matemática e EJA, Ribeiro e Darsie (2012) analisam:

Como se configura a produção acadêmica das pesquisas no campo da Educação Matemática de Jovens e Adultos a partir do estado da arte das teses e dissertações relacionando Educação Matemática e EJA, produzidas no Brasil no período de 2000 a 2010? (RIBEIRO; DARSIE, 2012, p. 3).

Em outro estudo, Ribeiro e Darsie (2016) afirmam que as teses no campo da Educação Matemática e EJA

Não apenas reafirmam aspectos pertinentes ao processo de ensinoaprendizagem da Matemática na EJA tratados por teóricos da área e pelas Diretrizes Curriculares Nacionais para a EJA, como acrescentam outros elementos importantes à consolidação de práticas pedagógicas e à formação docente. (RIBEIRO; DARSIE, 2016, p. 12).

Em outros estudos que realizam o estado da arte sobre a Educação Matemática e a EJA, encontramos Ribeiro (2014) analisando pesquisas que buscavam significados e percepções de alunos em relação à Matemática e ao seu processo de ensino-aprendizagem. Ele afirma ter verificado uma diversidade de aspectos da Matemática na sua relação com as dificuldades de aprendizagem de conteúdo, a variedade linguística dos alunos, a evasão escolar, dentre outros. O autor afirma também, que na percepção dos educandos da EJA, muitas vezes não acreditam serem capazes de apreenderem os conteúdos institucionalizados e mesmo os que se julgam capazes, sentem como empecilho as condições financeiras que impedem a aprendizagem de Matemática e "denotam não aceitar as suas variedades 
linguísticas como algo que possa ser digno de utilização no ambiente escolar, julgando-as como 'inferiores', e destacando que quem fala 'bonito' são pessoas inteligentes." (RIBEIRO, 2014, p. 126-127).

Também realizaram estado da arte sobre a Educação Matemática e a EJA Silva e Brandalise (2016). Segundo elas, a maioria das pesquisas catalogadas tem como temas

O processo ensino-aprendizagem de Matemática na EJA, com ênfase nas metodologias de ensino; resolução de problemas, jogos, modelagem matemática e nas áreas de geometria, tratamento da informação, números e operações. (SILVA; BRANDALISE, 2016, p. 216).

No estudo por elas apresentado, vale destacar que as questões relacionadas ao ensino na EJA e à área de Matemática tem se intensificado e contribuem com as especificidades didático-pedagógicas que a EJA requer. Para as autoras, mesmo que os documentos oficiais definam as diretrizes para esta modalidade "certamente existem lacunas, dificuldades e desafios para a efetivação de um ensino adequado nas características dos alunos que retornam aos estudos na fase adulta" (SILVA; BRANDALISE, 2016, p. 204).

O número de pesquisas que envolvem a Educação Matemática na EJA, as dificuldades dos educandos no processo ensino-aprendizagem, o perfil dos educandos EJA com suas potencialidades e suas dificuldades denotam a importância de se voltar os olhos para esta área, para esta modalidade, para estes sujeitos. E para além destes elementos ora apresentados, estamos no ano de 2020. Este é um ano em que um novo universo se configurou para o mundo, para o Brasil, para a sociedade, para a educação e chegou no "chão da escola" ou, melhor caracterizando, chegou "na nuvem" da escola.

O início de 2020 foi marcado pelo redimensionamento das relações, pelo temor, pelo SARS-CoV-2, pela pandemia que uniu todos os continentes em uma similitude "mascarada". $\mathrm{E}$, neste contexto, a escola, lócus privilegiado de relações interpessoais, de toque, de abraços, de companheirismo, de convivência e de aprendizado, foi a mais afetada. A similitude no uso mundial da máscara foi também a de fechamento dos espaços educativos no mundo. No município de Jataí, estado de Goiás - e em todo o Estado -, as aulas presenciais foram suspensas no mês de março para todos os níveis e modalidades de ensino. Nos meses seguintes as aulas continuaram suspensas. No entanto, para a modalidade EJA na rede pública estadual, as aulas foram retomadas no modelo de aulas remotas, já no mês de abril, com a justificativa de que, por ser curso desenvolvido em poucos meses, a suspensão das aulas prejudicaria o semestre letivo.

No mês de fevereiro, antes do início da pandemia, iniciou-se a primeira etapa de uma pesquisa que tinha como objeto o acompanhamento de dez educandos EJA em cinco municípios no estado de Goiás. Este acompanhamento é realizado durante um semestre letivo e tem como objetivo, verificar o desenvolvimento dos educandos nas disciplinas de Ciências e Matemática - no caso de EJA primeiro segmento - e de Biologia, Física, Química e Matemática - no caso de EJA segundo segmento. São selecionados, voluntariamente, alunos com maiores dificuldades e/ou com desejo em participar e contribuir para o desenvolvimento da pesquisa. Orientados pelos pesquisadores que explicam as características da pesquisa, os educandos definem se têm interesse em participar, assinando o Termo de Consentimento Livre e Esclarecido (TCLE).

Em 2020, no município de Jataí, que conta com 102.065 habitantes, população estimada pelo IBGE (2020), havia a oferta da EJA por instituições de ensino: municipal (1), 
estadual (2) e federal (1). Optou-se por realizar a pesquisa em duas escolas, uma da rede pública municipal e uma escola pública federal. Nas duas escolas o acompanhamento se deu na disciplina de Matemática, visto ser a disciplina que os educandos apontaram terem mais dificuldades ou, no caso de Cecília, a disciplina que ela mais gosta. Para este artigo optou-se em apresentar um recorte dos dados coletados em 2020. Relata-se a história de Cecília (nome fictício), educanda EJA no munícipio de Jataí-GO, seus anseios e sua relação com a Matemática que, como ela mesma diz, é uma disciplina que gosta muito, mesmo tendo, às vezes, alguma dificuldade.

Cecília é educanda EJA em uma escola pública federal em um curso técnico integrado ao ensino médio, na modalidade EJA em Secretariado. O curso é presencial, ministrado no período noturno, com duração de quatro anos. As aulas nesta escola foram suspensas no mês de março e, ao contrário da rede pública estadual, que iniciou as aulas remotas na EJA no mês de abril, as aulas remotas para todos os níveis e modalidades só foram retomadas no final do mês de agosto. $O$ presente artigo se divide em três tópicos nos quais serão apresentados: a história de vida da educanda Cecília, sua relação com o ensino remoto e as dificuldades por ela enfrentadas; a pandemia no Brasil e as aulas remotas; o ensino remoto e o processo ensino-aprendizagem na escola pesquisada.

\section{0 acompanhamento da educanda e suas dificuldades}

O primeiro contato com a aluna e a primeira entrevista realizou-se de forma presencial, no mês de fevereiro, antes do período da pandemia. Na primeira entrevista buscou-se o relato da história de vida e de suas dificuldades. O acompanhamento seria realizado presencialmente, seriam observadas as aulas e o objetivo era, ao final do semestre, apresentar uma proposta de ensino abordando os conteúdos nos quais a educanda tivesse mais dificuldades. Em função da pandemia, a coleta de dados foi redimensionada e passou a ocorrer também de forma remota, por telefone. Visando verificar como a instituição estava lidando com a suspensão das aulas e como os educandos percebiam a questão do isolamento, optou-se por realizar também entrevistas com a coordenação do curso na modalidade EJA.

Para a coleta de dados com a educanda, que frequenta o primeiro período, buscou-se analisar os motivos pelos quais se afastou da escola; apontar os principais motivos de retorno aos estudos; as dificuldades encontradas no passado e no presente; as contribuições almejadas pelo retorno aos estudos, dentre outras informações. Cecília foi uma das educandas que concordou em participar da pesquisa e foi selecionada em função da sua história com a Matemática. Após o primeiro contato concordou em participar, se colocando à disposição para ser entrevistada (a princípio por meio de um questionário a ser preenchido e posteriormente, por meio de uma entrevista com questões semiestruturadas). Diante das perguntas levantadas, segue a história de vida da educanda.

Cecília tem 25 anos de idade, é casada, tem dois filhos, nasceu no munícipio de Doverlândia-GO e mudou-se para Jataí em 2013. Nestes últimos sete anos retornou para Doverlândia onde permaneceu por dois anos. Depois, por questões de trabalho, decidiu morar em Jataí novamente. Essa mudança para Jataí se deu pelo fato de seu esposo, também natural de Doverlândia, ter se mudado em busca de trabalho. Assim, Cecília decidiu acompanhar o esposo, que, por motivos de saúde, não possui emprego fixo, faz apenas "bicos" para complementar a renda familiar, disse ela. Ela relatou que seu esposo teve paralisia infantil e por esse motivo recebe uma pensão do Instituto Nacional de Seguridade Social (INSS), o que faz com que ele complemente a renda com trabalho informal. A atividade diária de Cecília é 
cuidar do lar e de sua família. Ela cursou até o 20 ano do ensino médio, mas parou os estudos para cuidar dos filhos e, até a entrada no curso de Secretariado, em 2020, encontrava-se afastada da escola havia seis anos. Ela relatou que seu afastamento da escola por tanto tempo, foi motivado pela criação e zelo do seu primeiro filho, pois na época havia se mudado para Jataí e não tinha com quem deixar a criança para se dedicar aos estudos.

Como na realidade explicitada por Cecília, a EJA é o local de muitas outras histórias semelhantes de mulheres que se dedicaram a família e, por este motivo, decidiram abrir mão dos estudos, mulheres que precisam escolher entre trabalhar e estudar, geralmente optando pelo trabalho, para complementar a renda familiar, mulheres que são excluídas da escola por questões sociais, econômicas e culturais. As dificuldades que levaram a educanda Cecília a deixar a escola vão além da necessidade de cuidar dos filhos, pois, sem perceber ou sem entender, ela deixou a escola por motivos maiores, por razões históricas que excluíram membros de gerações anteriores de sua família, deixando como legado a realidade que vive hoje, não permitindo a ela, na idade regular, obter a formação em nível básico, conforme regimenta a Lei de Diretrizes e Bases da Educação Nacional, Lei 9.394/1996, não ter condições econômicas, refletindo numa exclusão social e/ou cultural, que não a permitiu seguir seus estudos. Quanto às motivações para retornar aos estudos,

Cecília: almejo ter uma vida mais digna, de modo a prover um futuro melhor.

(Diálogo da aluna, 2020).

Cecília decidiu voltar aos estudos e assim investir na possibilidade de ter uma profissão melhor, que lhe permita inserir-se no mercado de trabalho, com qualidade de vida e boas oportunidades profissionais. Analisando a história da educanda foi possível perceber, como afirmou Mariotti (2000), que a inclusão mais exclui do que inclui; que a mulher tem seus direitos, porém as barreiras que esta encontra diante do meio social, "afogam" sua capacidade de sonhar, não permitem a ela ter o direito de ter cultura, de ter uma formação de qualidade, de ter bem estar material, de ter qualidade de vida, tudo porque ela não se adequa aos índices que a política econômica deseja.

Sabe-se que enquanto é interessante investir em um programa popular como a alfabetização de pessoas analfabetas, há discursos, investimento e publicidade, porém quando outras variáveis, como saúde e segurança, por exemplo, são o destaque nos gráficos socioeconômicos, a educação das pessoas jovens e adultas é deixada de lado. Para Scortegagna e Oliveira (2006), a EJA se destaca na história da educação como alvo interesses "num verdadeiro choque político ideológico" (p. 3).

No que se refere às dificuldades de aprendizagem, Cecília alegou que sempre teve dificuldades em Biologia. Segundo ela, o método de explicação dos professores era confuso, não entendia o que falavam e as provas eram difíceis. Por muitas vezes os professores demonstravam não querer tirar as dúvidas da turma, fazendo com que ela guardasse para si suas dificuldades e/ou não entendesse o conteúdo. Análise de situações semelhantes é desenvolvida por Dowbor (2008), quando aborda a postura do professor, segundo ela, este pode assumir um posicionamento autoritário ou democrático e, mesmo o professor democrático possui atitudes autoritárias, mas que a melhor postura do professor é ser democrático, no sentido em que cria com seu aluno uma relação de diálogo. Sobre sua relação com a disciplina de Matemática, Cecília afirmou que no ensino fundamental sempre foi a disciplina preferida dela, no entanto, no ensino médio passou a ter um pouco de dificuldades, sobretudo com os conteúdos algébricos, que envolvem as variáveis. Apesar disso, a aluna continua a assumir uma postura positiva quanto a Matemática. 
Cecília sobre a Matemática: gosto muito.

(Diálogo da aluna, 2020).

Neste ano de 2020, Cecília disse que sua principal dificuldade para frequentar a escola é a locomoção, pois, por morar em um bairro distante da instituição escolar, o transporte público não atende suas necessidades. Em relação à escola,

Cecilia: Eu imaginava que a instituição escolar era boa, mas confesso que superou as minhas expectativas.

(Diálogo da aluna, 2020).

Segundo ela, a instituição possui excelente estrutura física, salas de aulas organizadas e limpas, há ar condicionado nas salas, professores usam notebook e projetor multimídias, o laboratório de informática é organizado e possui computador para todos os educandos, tem uma biblioteca grande, além de os educandos receberem um auxílio para alimentação. Quanto ao curso,

Cecília: Eu avalio o curso em uma nota de 0 a 10, em DEZ!

Cecilia: os professores são ótimos, escola muito organizada e estrutura muito bonita.

(Diálogo da aluna, 2020).

Sobre o tempo para estudos, Cecília afirmou poder se dedicar, visto que possui tempo livre para isso, pois conta com o apoio do esposo para cuidar dos filhos enquanto está na escola. Diante dessa realidade aqui abordada, Cecília apresentou como motivo para deixar a escola, a opção de cuidar da família, dos filhos, de estar ao lado de seu esposo, cujo desejo era buscar novos horizontes em busca de melhores condições de vida e trabalho. São inúmeros os motivos que levaram Cecília a deixar a escola, que se verificam também em uma leitura histórica do desenvolvimento da sociedade brasileira e vão além dos motivos aqui mencionados por ela, tem a ver com questões sociais, culturais e econômicas. Percebemos quantas são as dificuldades para que ela tenha acesso a direitos tão básicos, como a educação, por exemplo.

É por meio desse direito básico, a educação, que a sociedade vigente poderá gerar mudanças, mudanças essas que talvez a nossa geração não possa usufruir. Porém, se colocando no lugar do outro, entendemos que outras gerações poderão usufruir de mais direitos, com melhor qualidade de vida, com participação ativa, com o respeito e valorização da cultura diversa, pois segundo Freire (2000, p. 67), "se a educação sozinha não transforma a sociedade, sem ela tampouco a sociedade muda".

\section{A pandemia no Brasil e o ensino remoto}

A entrevista inicial, feita no mês de fevereiro de 2020, precedeu uma crise na saúde mundial, motivada pelo SARS-CoV-12, a doença COVID-19 levou diversos países no mundo a terem um colapso no sistema de saúde, ocasionando milhares de mortes e no Brasil não foi diferente. No contexto da educação, as instituições de ensino, do nível básico ao superior, incluindo a pós-graduação, seguiram as orientações da Organização Mundial de Saúde (OMS) e suspenderam suas atividades presenciais. No entanto, a educação também sofreu com tomadas de decisões erradas, imposição para o retorno das atividades escolares, com calendários reformulados com o aval do Ministério da Educação (MEC), em modo remoto. Definimos como decisão errada, porque não houve a preocupação em estudar se tanto os milhares de professores, quanto os milhares de educandos, teriam estrutura, recursos, estabilidade psicológica e emocional para o retorno dessas atividades de modo remoto. 
A realidade vivenciada no ano de 2020 demonstrou que o professor precisa se organizar para ter um ambiente com boa acústica, material básico para expor conteúdo, tais como: quadro, mesa digitalizadora, notebook, computador, tablet, celular, filmadora, aparelhos de som e iluminação, dentre outros, tudo isso, em um local que antes era seu lar, seu refúgio pessoal e hoje se distorce entre vida privada invadida e vida profissional conturbada; além do desgaste mental de estar à disposição para atender essa demanda emergencial que os pegou completamente despreparados. Do outro lado, temos os educandos, que precisam do celular smartphone dos pais, quando não tem o seu (realidade em muitas famílias brasileiras), que necessitam de dados móveis (que muitas vezes são prépagos) e, caso tenha uma vida um pouco melhor (financeiramente), possuindo um computador ou notebook, este, muitas vezes, é a única ferramenta em um lar com demanda para várias pessoas, pois há mais de um filho em idade escolar e o pai e/ou a mãe "privilegiados" com home office.

O Grupo de Pesquisa Educação, Comunicação e Tecnologias, da Faculdade de Educação da Universidade Federal da Bahia publicou reflexões sobre problemas que circundam o ensino remoto no Brasil (PRETTO; BONILLA; SENA, 2020). Segundo eles,

A preocupação com a suspensão das aulas e, mais do que tudo, com a educação das crianças, se mescla às demais dificuldades enfrentadas pelas famílias, sobretudo, quando os modelos e rotinas das aulas remotas não são capazes de dialogar e contribuir com a organização do cotidiano familiar, tornando-se, na verdade, mais um dos problemas a serem enfrentados. (PRETTO; BONILLA; SENA, 2020, p. 3).

Eles afirmam que as escolas e universidades, com as tentativas de fazerem um ensino remoto revelam uma realidade até então oculta na sociedade brasileira: as dificuldades das famílias mais pobres em acompanharem as atividades propostas, principalmente em razão das desigualdades sociais e econômicas.

Para as famílias cujos pais estão no 'trabalho remoto' em casa (= homeoffice) - e que os desabafos convertidos em memes evidenciam que nada têm de home, são somente office -, a responsabilidade pelo acompanhamento dos filhos não tem funcionado muito bem. (PRETTO; BONILLA; SENA, 2020, p. 11).

Para eles, replicar a rotina escolar no ambiente doméstico levou os pais ou responsáveis a um estado crescente de estresse. Para além destes aspectos familiares os autores chamam também a atenção para as questões econômicas ligadas ao modelo de ensino remoto:

Nesse ínterim, rapidamente, as grandes empresas e plataformas digitais (Microsoft, Google, Facebook, entre outras), que ao longo dos tempos recentes vêm buscando, de forma insistente, estarem presentes nos sistemas de educação, tanto privado como público (tendo uma pequena e heroica resistência nesse último caso), anunciam planos mirabolantes, colocando à disposição, 'gratuitamente', todos os seus recursos para que a educação continue, apesar da pandemia. (PRETTO; BONILLA; SENA, 2020, p. 11). 
Para os autores, tem-se uma corrida para dar uma rápida resposta social frente ao período da pandemia o que tem resultado em parcerias que refletem um projeto de "desvalorização da formação dos sujeitos, de privatização da educação pública e do fortalecimento dos valores do capital na educação" (PRETTO; BONILLA; SENA, 2020, p. 11). Eles salientam que, com estas parcerias, corre-se o risco também de que estas empresas tenham acesso aos dados: das escolas; dos alunos; dos professores e até mesmo dos pais, o que resultaria em uma fonte de controle e vigilância sobre uma grande parcela da população.

Ao analisar as mudanças que se processam no mundo em função da pandemia, Santos (2020, p. 5), faz analogia com um debate comum nas ciências sociais dizendo que "tudo que é sólido se desfaz no ar" e elenca seis elementos para debate: a normalidade da exceção quando afirma que a crise do vírus apenas veio agravar uma crise sócio-econômica-cultural já existente; a elasticidade do social - ele mostra que as mudanças que se processam na sociedade são lentas e um período de crise não coaduna com morosidade; a fragilidade do humano - retrata como a segurança se esvai durante uma crise e a contradição presente nas relações, pois se você quer proteger (se), a melhor maneira é isolar (se); os fins não justificam os meios - ele retrata também a contradição entre a redução do comércio, do consumo e das vidas humanas, mas a melhoria da diminuição da poluição atmosférica, citando também como a democracia é ameaçada pelas fake news; a guerra de que é feita a paz - ele analisa que o mundo se voltou contra a China que, paralelamente evoluía para uma potência econômica mundial e que a OMS ainda não conseguiu definir qual é a origem do vírus; a sociologia das ausências - para ele a pandemia provocou uma comoção mundial sem, no entanto, voltar os olhos para os refugiados, as populações pobres que ele chama de "invisíveis", na Europa, nas Américas. Segundo ele, "os debates culturais, políticos e ideológicos do nosso tempo têm uma opacidade estranha que decorre da sua distância em relação ao quotidiano vivido pela grande maioria da população, os cidadãos comuns" (SANTOS, 2020, p. 10).

Para realizar o debate e analisar os períodos de quarentena estabelecidos em todo o mundo, Santos (2020) chama a atenção para os grupos para os quais a quarentena é difícil, retratando: as mulheres; os trabalhadores precários, informais, ditos autônomos; os trabalhadores da rua - camelôs, entregadores; os sem-abrigo ou populações de rua; os moradores das periferias das cidades ou favelas; os internados em campos para refugiados, imigrantes, sem documentos ou populações deslocadas internamente; as pessoas com deficiência; os idosos. Segundo ele, a quarentena reforça a injustiça, a discriminação, a exclusão social e o sofrimento.

Pamplona e Oliveira (2020) também analisam a pandemia e estabelecem seu efeito panóptico na educação se fundamentando em conceitos foucaltianos. Segundo eles, existem muitas possibilidades de análises

Das circunstâncias em que se assumiram as atividades pedagógicas virtuais, de como uma rede microscópica de poder perpassa de mãos em mãos, criando verdades, e talvez de modo inédito, acentuado, executando uma captura em âmbito virtual. (PAMPLONA; OLIVEIRA, 2020, p. 4-5).

Para eles esse poder transita "em rede, com fino deslize, sem dono, ele se entrelaça e arquiteta verdades, valendo-se dos próprios saberes epistêmicos" (p. 6). O ensino virtual, dizem eles, acentua a exclusão e a homogeneização visto que não alcança a maioria dos estudantes, ou, se alcança, o faz de maneira inerte - é um dado cibernético quantificável, no entanto anônimo, sem presença afetiva e efetiva. Assim, 
A pasteurização do ensino virtual em meio à crise pandêmica desloca o sentir para o frio campo do saber-poder, congelante e mortífero. Parece que o vírus não ensinou o suficiente sobre a precariedade, transitoriedade da vida. (PAMPLONA; OLIVEIRA, 2020, p. 15).

Para eles a educação escolar não deveria prender os estudantes nas "grades panópticas digitais", deveria sim abrir para a vida - com suas belezas, cores e aromas. No entanto, para que isso se efetive seria preciso ver, ouvir e sentir as pessoas em um eterno processo de aprendizagem e só assim a própria vida emergiria numa reconstrução da vida escolar de forma inovadora e artística.

Também debatem a educação no Brasil em tempos de pandemia, sob conceitos foucaltianos, Saraiva, Traversini e Lockmann (2020). Analisando os efeitos do ensino remoto, afirmam que a suspensão das atividades presenciais nas escolas não significou diminuição de atividades de docentes e de alunos, pelo contrário, houve uma invasão dos espaços domésticos e sobrecarga de atividades, que resultaram também em maior controle. No ensino remoto, dizem elas, "é necessário, em geral, um envio de evidências de desenvolvimento de atividades não avaliativas, que funcionam como uma forma de controle do uso do tempo, uma das características da disciplina" (SARAIVA; TRAVERSINI; LOCKMANN, 2020, p. 7). As autoras afirmam que houve uma multiplicação dos vigias que ganharam competências punitivas: pais sobre os filhos; gestores (e pais) sobre educadores. Segundo elas, dissolveram-se os muros das escolas que entraram na sala da casa expondo os professores aos olhares das famílias. Neste sentido, a docência em tempos de pandemia é exausta, ansiosa e preocupada, e caminha em meio a adversidades e incertezas (SARAIVA; TRAVERSINI; LOCKMANN, 2020).

Sobre a Educação Matemática no período da pandemia, Idoeta (2020) fala sobre as dificuldades que as pessoas possuem em ler gráficos, tabelas, entender as estatísticas e que isto se deve à forma como a Matemática é ensinada. "No Brasil, só $16 \%$ dos alunos concluem o ensino fundamental ( $9^{\circ}$ ano) com aprendizado adequado em matemática, segundo os dados da Prova Brasil 2017" (IDOETA, 2020, s/p). Ela afirma que não apenas no Brasil isto ocorre, os currículos não preparam os alunos para a leitura de dados. Segundo ela, ser alfabetizado em dados "significa ser capaz de entender números, gráficos, probabilidades ou questões lógicas, por exemplo, e conseguir usar esses dados para entender padrões ou mesmo tomar decisões" $(s / p)$. Ao afirmar que errar na Matemática é sinal de crescimento a autora destaca a crítica sobre

A ênfase do ensino tradicional na memorização, na quantidade de acertos das crianças e na rapidez com a que elas resolvem os exercícios. Os argumentos contra isso são de que 1) a memorização está desprovida de significado, 2) valorizar a rapidez desestimula a maior parte dos estudantes, e 3) de que o erro e o esforço para corrigi-lo são, na verdade, uma oportunidade de formar novos caminhos neurais no cérebro, que vão ajudar o aluno a de fato aprender matemática. (IDOETA, 2020, s/p).

A autora afirma que mesmo havendo a percepção de que a pandemia irá mudar a dinâmica das escolas e a Educação Matemática, ainda não se tem noção de como isto irá se efetivar. É preciso se adaptar ao "novo normal", como afirmam Oliveira e Carreiro (2020), Prado (2020) e Schirato (2020). Este modelo de educação implantado em diversas regiões no país - resultado dos isolamentos sociais decretados em função da pandemia - é o mesmo que a pesquisa cujos resultados são aqui apresentados detectou. Por toda a mídia divulgou-se 
sobre as dificuldades de educadores, educandos, pais e gestores em se adaptarem ao que se divulga como "novo normal" e foi a este novo normal na Matemática, por meio do ensino remoto que Cecília precisou se adaptar.

Analisando os efeitos da pandemia na educação matemática a Sociedade Brasileira de Educação Matemática - RS promoveu um ciclo de palestras em 2020 e uma delas foi publicada. Nesta, Souza e Silva (2021) relatam sobre as mudanças pelas quais a educação matemática teve que passar para se adaptar ao ensino remoto. Segundo eles, são necessárias ações pedagógicas "que possam engajar os estudantes e fazê-los desenvolver, com autonomia e responsabilidade, a construção de conceitos matemáticos, sejam eles elementares ou não" (SOUZA; SILVA, 2021, p. 34). Ao analisarem a necessidade da ressignificação da Matemática na EJA os autores afirmam que o público da EJA tem medo de errar, de se colocar frente aos problemas, de argumentar. Neste sentido, é importante "observar e destacar o quanto esse medo pode ser potencializado em aulas de Matemática" (p. 44). Para os autores, as aulas síncronas foram fundamentais para que os alunos debatessem e construíssem os conceitos matemáticos.

\title{
$4 \quad 0$ ensino remoto e o processo ensino-aprendizagem na escola pesquisada
}

A realidade encontrada em Jataí-Go, lócus da pesquisa aqui apresentada, não difere do que vimos no país. Na escola onde Cecília frequenta a EJA, o calendário 2020 foi suspenso de 16 de março de 2020 (no dia 17 de março de 2020, de acordo com a Portaria 343/2020 emitida pelo MEC, teve as aulas suspensas em âmbito nacional) até 30 de agosto de 2020, quando houve o retorno do calendário, com aulas desenvolvidas de forma assíncrona e síncrona, retornando assim com as atividades de ensino, pesquisa e extensão.

Com a suspensão das aulas, o acompanhamento previsto na pesquisa foi suspenso e os novos contatos/entrevistas com a educanda Cecília foram realizados por telefone, via WhatsApp. Ela então fez um relato sobre os reflexos desse momento social que incidiu sobre sua vida enquanto mulher, aluna, mãe e cidadã. Sobre os efeitos da pandemia nas vidas das mulheres Pamplona e Oliveira (2020, p. 10) afirmam que

\begin{abstract}
As mulheres brasileiras, durante a pandemia de coronavírus/Covid-19, estão mais sobrecarregadas com: atividades domésticas, cuidados com crianças, pessoas idosas e com deficiências, em especial àquelas que possuem baixa renda orçamentária. Assim, o questionamento de como essas mulheres podem ter desempenhos acadêmicos satisfatórios, nesse período, é um fator que necessita ser colocado em pauta e problematizado. (PAMPLONA; OLIVEIRA, 2020, p. 10).
\end{abstract}

Esta realidade apontada por Pamplona e Oliveira (2020), é também a realidade vivenciada por Cecília. Segundo ela, durante esse tempo de distanciamento social (março a agosto de 2020) não teve nenhuma atividade escolar, mesmo que de modo remoto. Ela alega que durante o pouco tempo que tiveram aulas presencias, antes da pandemia e da suspensão do calendário, poucas atividades foram desenvolvidas e, por cursar o primeiro período do curso de Secretariado, não havia material suficiente para uma revisão e estudos posteriores diante da suspensão do calendário. Ela relatou que fez algumas leituras referentes ao conteúdo que tinha no caderno, visando não desanimar dos estudos que retornariam posteriormente. Disse também que estava ansiosa com o retorno das aulas, esperando que começassem logo, mesmo de modo remoto. 
Cecília afirmou que o ruim dessa pandemia foi não poder viajar para estar junto dos seus familiares - como relatado, ela é da cidade de Doverlândia e não possui familiares em Jataí, onde reside hoje, pois todos são de outras cidades - e ela sente a necessidade em ter seus familiares por perto, em convívio mais próximo. Além disso, ela relata que seu esposo ficou sem trabalho, os "bicos" que fazia para complementar a renda familiar ficaram escassos, pois o distanciamento social levou ao fechamento do comércio impedindo-o de encontrar serviços informais. No entanto, com a flexibilização das regras de funcionamento do comércio e dos serviços em geral (em setembro de 2020), o esposo de Cecília, aos poucos tem conseguido arrumar algum trabalho esporádico. Outro ponto positivo foi a liberação do auxílio emergencial, por ter cadastro único no programa bolsa família, o benefício emergencial veio automaticamente para sua conta e segundo ela, está ajudando bastante. Apesar das inúmeras críticas que se fazem em relação aos programas sociais, percebemos que este auxílio ainda é pouco quando se pensa na dívida social que a política brasileira tem para com pessoas como Cecília e seu esposo. É necessário dar subsídios a essas famílias, dar a elas o que é de direito, como saúde, educação, segurança, cultura, lazer. São requisitos básicos que uma sociedade necessita para ter qualidade de vida.

Outro contexto abordado por Cecília é a condição de mãe diante da pandemia. Seus filhos em idade escolar estão desenvolvendo as atividades que a escola envia, seja em formato PDF no seu celular, seja impresso, entregue todas as sextas-feiras. Cecília afirmou que o material impresso foi disponibilizado desde que o ensino remoto foi instituído na rede pública municipal, onde seus filhos estudam. A princípio, Cecília dirigia-se até a escola para coletar o material. Como a escola ficava longe de sua residência, ela passou a receber o material por email e fazer a impressão do mesmo para que seu filho resolvesse e após as atividades prontas, tirava a foto e enviava para a professora, via WhatsApp ou e-mail da instituição escolar. Ela, assim como muitas famílias, teve que se desdobrar com a rotina doméstica, os cuidados com a família e os estudos dos filhos, que semana após semana, demandam um número considerável de atividades para serem orientadas por esta mãe atribulada de afazeres, que com o retorno de suas próprias atividades escolares, também teve que ter foco e organização. Mas Cecília não se mostra desmotivada não. Após cada um desses relatos, ela tem se demonstrado otimista com dias melhores, com novas possibilidades e novos projetos de vida.

No que tange aos estudos em casa, Cecília relatou, como dito anteriormente, seu fascínio com a disciplina de Matemática e lamentou não ter tido professor de Matemática, pois a instituição aguardava a posse do candidato contratado temporariamente para assumir a disciplina. Como reação, não havendo material e atividades que pudesse revisar e/ou estudar, não houve a possibilidade de se reforçar os estudos da Matemática. Entretanto, durante a pandemia, ela disse ter feito leituras do material ministrado em outras disciplinas que teve aulas antes da pandemia, tais como: Biologia e Língua Portuguesa.

Quando questionada sobre o retorno das aulas, se havia alguma preocupação quanto a isso, Cecília disse que estava animada com o retorno das atividades, porém algumas preocupações a intrigavam, como o desenvolvimento das disciplinas, com a sequência de conteúdos, atividades e avaliações que serão desenvolvidas em um prazo mais curto, devido a adequações no cumprimento do calendário. Mesmo assim, ela mantinha-se otimista, porém com uma ansiedade quanto ao retorno das aulas. Ela falou também que a instituição, diante desse retorno das aulas de forma síncrona e assíncrona, tem fornecido recursos e meios para o melhor desenvolvimento das aulas remotas, permitindo que os educandos consigam acompanhar as aulas. Cecília afirmou que não possui internet em casa e nem computador, 
mas a instituição tem promovido ações para que esses estudantes tenham todo o suporte necessário. Ela disse que foi contemplada em edital institucional para receber o auxílio emergencial conectividade, que visa dar condições de acesso à internet por meio de pacote de dados móveis ou auxílio financeiro, no valor de $\mathrm{R} \$ 100,00$ mensais. O benefício foi concedido aos estudantes em situação de vulnerabilidade socioeconômica, durante a realização de aulas on-line (Ensino Remoto Emergencial), enquanto permanecer a pandemia. Além deste auxílio, Cecília também recebeu equipamentos (computadores com todos os hardwares e/ou periféricos) cedidos pela instituição para o prazo que se fizer necessário e/ou enquanto durar o desenvolvimento das atividades acadêmicas de modo remoto.

Cecília é representante dos alunos do curso e, por este motivo, teve acesso imediato às informações sobre os auxílios, o empréstimo dos equipamentos disponíveis para atendimento aos alunos para o desenvolvimento das aulas de modo remoto. Além disso, os discentes do curso de Secretariado/EJA têm direito ao auxílio permanência e alimentação. No início do ano letivo, os estudantes fizeram o cadastro com a entrega das documentações referentes aos auxílios mencionados e quando foram disponibilizados os auxílios para dados (internet) e equipamentos (computador e hardwares), o cadastro para participar foi automático. Para isto, os educandos participaram de uma pesquisa com o preenchimento de questionários sobre a sua condição para assistir as aulas remotas e o retorno do calendário e as atividades de ensino, pesquisa e extensão de modo remoto. Os recursos disponibilizados pela instituição foram importantes para Cecília, pois ela não possuía computador, apenas celular e este não tem boa capacidade de memória e já estava impossibilitado de uso contínuo, pois

Cecília: travava e desligava.

(Diálogo da aluna, 2020).

Além disso, a internet disponível era somente os dados móveis do celular. Com o auxílio, a estudante adquiriu internet de dados e, com o equipamento cedido, ela consegue participar das aulas e desenvolver as atividades propostas. Ela se sente privilegiada em estudar numa instituição que ofertou subsídios necessários para que seus estudantes acompanhassem as aulas remotas e cumprissem com as atividades curriculares. Os recursos disponibilizados facilitaram inclusive os estudos para o filho de Cecília, que estuda na rede municipal de educação e cursa o Jardim II. Antes de ter o computador em casa ela tinha acesso aos materiais de estudo do filho uma vez por semana, por e-mail, imprimia, seu filho resolvia as atividades solicitadas e ela enviava a foto das atividades resolvidas. Posteriormente, o filho de Cecília passou a ter videoaulas disponibilizadas em três dias da semana. Com o computador, o filho acessa os vídeos que são disponibilizados por e-mail para aqueles que não conseguem assistir em tempo real. Ela é quem auxilia o filho no cumprimento dos deveres da escola, pois seu esposo, devido ao trabalho, tem menos tempo para o acompanhamento dos estudos dos filhos.

Sobre as dificuldades enfrentadas por Cecília na disciplina Matemática com o retorno das aulas de modo remoto, ela afirmou que as aulas remotas dificultaram a aprendizagem Matemática, pois durante as aulas não presenciais o tempo de diálogo, de acesso ao professor para tirar dúvidas, para expor os conceitos de forma mais clara, não se compara as aulas presenciais. Segundo ela, essa relação "corpo a corpo", "olho no olho", faz a diferença nas inter-relações entre professor e aluno, o que facilita o conhecimento das dificuldades do educando pelo educador. Sobre esta questão Giancaterino (2009, p. 17) afirma que: 
O processo de ensino aprendizagem é uma construção continua e notável, onde requerem de nós, professores, independentemente de sua cátedra, constante adaptação para que possamos retirar dos processos o melhor e aproveitar todas as suas etapas, respeitando evidentemente sempre o grau de dificuldade de cada educando. (GIANCATERINO, 2009, p.17).

Um exemplo sobre dificuldades geradas no modo remoto, segundo ela, é que há momentos em que o aluno não possui o recurso de áudio para conversar com o professor em tempo real, restando o diálogo via chat. Durante alguma apresentação simultânea dos conceitos, o professor não tendo acesso ao chat em tempo real, não responde dúvidas escritas, isso faz com que as dúvidas levantadas sejam respondidas e/ou atendidas no pósapresentação e no avançar da aula, outras dúvidas se apresentam, acumulando e levando o aluno a se inibir quanto ao processo de diálogo e dificuldades. Fica claro aqui o quanto a atenção do professor ao lidar com diferentes recursos, metodologias, propostas educacionais, se torna sensível de percepção. O desenvolvimento de aulas de modo remoto gera uma sobrecarga de atenção, planejamento e organização por parte do educador e inibe a participação, o envolvimento e interesse do educando.

Para reforçar a ideia apresentada neste parágrafo sobre a diferença da aprendizagem desenvolvida no modo presencial e no modo remoto, Libâneo (1994, p. 82) enfatiza que:

\begin{abstract}
Existem dois tipos fundamentalmente diferentes de aprendizagem: a aprendizagem casual e a organizada. A aprendizagem casual é a aprendizagem espontânea, surge naturalmente da interação com outras pessoas, ou seja, do convívio social, pela observação de objetos e acontecimentos, pelos contatos com as mídias, leituras e conversas informais etc. Já a aprendizagem organizada tem caráter intencional, sistemático, cuja finalidade peculiar é a construção do conhecimento. (LIBÂNEO, 1994, p. 82).
\end{abstract}

Ao se apegar na fala do autor sobre a aprendizagem casual, nota-se que diante do contexto do ensino remoto, muitas das caracterizações apontadas não são passíveis de serem geradas nessa realidade, em que, a princípio, não se tem mais o convívio social saudável (gerado pela presença física, com o toque, o encontro do olhar, a troca de sorrisos) e as mídias se tornaram um recurso no qual o educando não sente mais o prazer em buscar para o enriquecimento do seu conhecimento, pois o convívio diário e em longo tempo com as mídias, e a rede, tiraram parte ou todo o prazer da interação com estas. Tais caracterizações são adjetivos do ensino presencial, que não serão alcançados/contemplados no modo remoto.

Quanto às atividades desenvolvidas no modo remoto, Cecília afirmou que foram poucas, devido ao tempo ter sido "corrido" para cumprir o calendário. Por serem poucas atividades, a aluna abordou também não haver muita cobrança quanto ao nível de dificuldade no processo de resolução das atividades:

Cecilia sobre as atividades: foram fáceis.

(Diálogo da aluna, 2020).

Diante desta fala, analisa-se que, devido ao pouco tempo de aula, desenvolvido no modo remoto, uma readequação dos planos de ensino foi implementada, de modo a definir atividades com "níveis de dificuldade" moderados ou básicos (com essa fala, considera-se moderados ou básicos, exercícios que não envolvam quase nenhuma ou nenhuma análise 
crítica, interpretação, como exemplo: questões contextualizadas, situações problemas cuja elaboração e solução partem da realidade do aluno). Quanto a se programar para os estudos e bom desempenho quanto ao cumprimento das tarefas,

Cecilia: me organizo para cumprir com as atividades.

(Diálogo da aluna, 2020).

A postura de Cecília ao se organizar para cumprir com as tarefas desenvolvidas neste momento de aulas remotas, surtiu o efeito da não acumulação e isso favoreceu também o bom desenvolvimento das atividades e avaliações. Quanto aos conteúdos propostos pela ementa, não foi possível cumprir com a mesma, devido ao tempo de aulas, a (re)adequação do currículo, o que se acredita que pode acarretar prejuízo ao educando. Cecília afirmou estar motivada e até considera que o ensino remoto tem pontos positivos, pois devido a um problema de saúde - fortes dores nas pernas - ela disse que se as aulas fossem presenciais, faltaria muito e as aulas remotas, estando em casa e tendo o apoio do esposo para cuidar dos filhos e assessorá-la, facilitam consideravelmente estar presente e assistir todas as aulas. Outra questão mencionada foi o transporte, que antes era um problema, devido ao não cumprimento dos horários, gerando atrasos. Com o ensino remoto, este problema deixou de existir, pois ela não precisa lidar com tais problemas para assistir às aulas. Sempre frequente e participativa, destaca no modelo remoto pontos positivos. Ainda assim, ela considera que se as aulas fossem desenvolvidas de modo presencial, seria melhor devido ao contato proximal e ao diálogo em tempo real sem intervenções externas. Em relação à conclusão dos estudos, quanto ao seu estímulo em continuar ou parar, Cecília disse que em nenhum momento pensou em desistir.

Cecilia: Espero com o curso arrumar um emprego para dar uma vida mais confortável aos meus filhos. Eu também quero poder pagar os meus estudos porque não penso em parar por aqui, pretendo fazer uma faculdade.

(Diálogo da aluna, 2020).

Percebe-se na fala de Cecília uma concepção sobre o papel da educação, como transformadora,

Uma concepção democrática de educação compreende, portanto, esse ser inacabado que somos, que é capaz de ser sujeito do seu processo de aprendizagem e é possuidor de uma história de vida única e uma forma de desejar, de pensar e de estar no mundo também única. (DOWBOR, 2008, p. 59).

Cecília, ao projetar planos futuros em que almeja melhores condições de vida para seus filhos e família, com o desejo em ter mais conhecimento, em se qualificar passando para o próximo nível, demonstra estar numa fase de autoconhecimento, onde sabe o que quer e quando quer.

Cecilia: não sou mais aquela jovem que um dia sonhou e talvez não tivesse a segurança em dizer que queria ir além.

(Diálogo da aluna, 2020).

Essa segurança é fruto da experiência, da vivência da realidade, onde se precisa tomar decisões que podem transformar por completo uma vida. Cecília deseja ir além, deseja fazer parte desse mundo que um dia lhe foi negado e acredita que o caminho para ter mais 
qualidade de vida e oportunidades acontecerá pela educação. Para ela, é por meio dos estudos e sua vontade de ir além, de alcançar o próximo nível (faculdade), que ela irá superar dificuldades que um dia foram barreiras em sua vida, que um dia a fizeram deixar a escola, acreditando que não era seu direito permanecer ali. Para conhecer a realidade da modalidade EJA na escola pesquisada realizou-se também uma entrevista com a coordenadora do curso frequentado por Cecília. Segundo ela, atua há dois anos na coordenação do curso e sobre as dificuldades em relação ao ensino noturno, apontou: atrasos na chegada para o início das aulas, muitos deles motivados pelo transporte público - devido à distância da instituição em relação à moradia da maioria dos educandos dependentes desse meio de locomoção - que geram atrasos devido ao não cumprimento dos horário/tempo de viagem; outro motivo é o trabalho, outro ponto que contribui para dificultar o ensino noturno, gerando atrasos e até a evasão. Segundo ela, geralmente as questões de horário de saída do serviço são, muitas vezes, impostas pelos empregadores como situação de escolha, colocando o aluno entre a escolha de trabalhar segundo a necessidade do empregador ou ficar sem emprego.

No que se refere às dificuldades de aprendizagem, a coordenadora relatou que muitos educandos procuram-na relatando que o tempo de afastamento da sala de aula dificulta o processo de assimilação e ensino-aprendizagem dos conteúdos abordados pelas disciplinas. Nesse contexto de ensino, algumas dificuldades dizem respeito às produções de atividades. Essas pessoas jovens e adultas alegam que, por serem trabalhadoras, muitas vezes não têm o tempo livre para o cumprimento da agenda de atividades e/ou estudos complementares. 0 cansaço após um longo dia de trabalho, com uma jornada cansativa, acaba por desmotivar e desanimar o cumprimento da agenda de estudos extraclasse. A coordenadora afirmou que exaustão e desmotivação, são sentimentos identificados como oriundos das atividades geradas pelo emprego/trabalho.

Sobre os motivos que levam os educandos a deixarem/voltarem para a escola a coordenadora apresentou dados de um levantamento realizado na instituição no período de 2016 a 2018, que apontaram uma média de 30 alunos matriculados e que os principais motivos relatados para o retorno aos estudos são: acompanhamento do ensino dos filhos: os estudantes alegam que, percebendo que seus filhos estão avançando nos estudos, necessitando de orientação para desenvolver as atividades propostas pela escola, veem nessa necessidade de auxílio o "gatilho" para prosseguir com os estudos que um dia abandonaram; o aperfeiçoamento para ascensão no mercado de trabalho: é apresentado e relatado pela maioria dos estudantes como motivação para voltar a se dedicar aos estudos. A necessidade de se qualificar para ter uma oportunidade de emprego com boa remuneração ou até mesmo para uma eventual promoção são os destaques desse motivo; retorno ao estudo devido à recuperação da saúde: um ponto relatado pela gestora, porém em menor proporção, é o fato de a pessoa ter se afastado dos estudos para se dedicar aos cuidados da própria saúde e/ou de um ente querido que sofre de alguma enfermidade. Por motivo de cura, em sua grande maioria, estes estudantes retornam para as salas de aulas para continuar o que, por motivo de força maior, foi obrigado a adiar.

Quando questionada sobre a evasão, dentre os motivos apontados, a coordenadora destacou: trabalho; dificuldades de compreensão dos conteúdos; transporte público (horário de saída do curso e as dificuldades em ter linha de ônibus em bairros distantes); questões pessoais (conjugue, gestação, familiares, filhos); ser aprovado no Exame Nacional para Certificação de Competências de Jovens e Adultos (Encceja) - avaliação externa que visa a aceleração para a obtenção da certificação do ensino médio - os alunos fazem a prova e 
conseguindo aprovação abandonam o curso; e tempo de conclusão do curso (o curso técnico em Secretariado, tem duração de quatro anos). A respeito das ações para lidar com a vulnerabilidade dos estudantes, a coordenadora afirmou que a instituição possui políticas de financiamento e oferece auxílio de 120 reais para alimentação, auxílio permanência, auxílio transporte e, para o retorno das aulas no modelo remoto, ofertou auxílio internet.

Ela também comentou que os atuais governos fizeram cortes na educação, que acarretaram deficiências no auxílio aos estudantes. Antes desses cortes, os estudantes recebiam uniforme e kit de materiais escolares. Sobre as ações acadêmicas que a instituição têm desenvolvido durante a pandemia para esses estudantes, a coordenadora afirmou que, na pandemia, algumas atividades remotas foram implementadas, porém, sem sucesso, pois com a falta de seguridade no processo de validação e obrigatoriedade no desenvolver dessas atividades, os estudantes pouco se envolveram, levando à extinção dessas atividades remotas até o final do primeiro semestre de 2020. Estas atividades remotas foram retomadas em agosto.

\section{Considerações finais}

A história de Cecília aqui relatada é a história de milhares de mulheres, que foram excluídas socialmente, que foram privadas de sonhar enquanto jovens, que abriram mão até mesmo da dignidade e ao falar de dignidade, faz-se referência à qualidade de vida, direito subjetivo da mulher, do homem, dos jovens, das crianças e dos idosos perante a nossa constituição federal, que relata em seus artigos caminhos democráticos para construir uma sociedade com cidadãos críticos, proativos, criativos, capazes de mudar o contexto social.

Cecília deixa o sentimento de que a nossa estrutura social, historicamente, possui lacunas que culminaram na realidade das gerações atuais. A história de Cecília representa a unidade do diverso, uma particularidade carregada de universalidade, uma totalidade percebida na singularidade de uma vida. Vida repleta de angústias, de contradições, mas também carregada de esperanças. As angústias, em 2020, foram entrecortadas pelo medo de um vírus que assola a humanidade, pelas apreensões com as aulas remotas, pelas dúvidas em relação à aprendizagem. Conforme afirmaram Pretto, Bonilla e Sena (2020), o contexto da pandemia não pode ser um elemento motivador para que a educação se faça de forma imediatista e desorganizada. Não se pode apenas transferir a forma de ensinar de presencial para remota seguindo os mesmos conteúdos.

$\mathrm{Na}$ escola pesquisada, durante os meses de março a julho de 2020, o calendário acadêmico ficou suspenso. Com isso, todas as atividades acadêmicas também foram paralisadas e só foram reiniciadas em agosto com a retomada do primeiro semestre letivo. Com o retorno do calendário 2020, alguns subsídios foram ofertados aos discentes, como forma de garantir uma estrutura mínima para o desenvolvimento das atividades escolares de modo remoto, modalidade optada pela instituição para o retorno das atividades com destaque para o auxílio financeiro para internet e empréstimo de equipamentos, como relatou Cecília. Verificou-se que a instituição adequou as atividades para as aulas remotas, o que reflete o cuidado em lembrar que o aluno da EJA é uma pessoa que trabalha, que não pode abrir mão de trabalhar para sobreviver, pois mesmo diante da situação pandêmica, este esteve sempre ativo na questão trabalho. A aluna afirmou que, tanto a instituição quanto os docentes do curso, tiveram a sensibilidade de planejar as aulas de modo remoto segundo tal contexto, tal público. Foi possível verificar também que a forma como o professor aborda o conceito dos conteúdos em que tem dificuldades dificulta o entendimento dos temas 
abordados e isto foi potencializado nas aulas remotas. Além disso, a aluna considera que a metodologia pode influenciar de modo positivo ou negativo, no processo de ensino aprendizagem da Matemática.

No entanto, a esperança se mantém e Cecília afirmou que sua maior expectativa para o pós-pandemia, o tempo em que a "não presença" cessar, é que as pessoas deverão valorizar os pequenos detalhes da vida, como sorriso, um aperto de mão, um abraço, ou seja, as relações proximais com o outro. Quanto à educação,

Cecilia: acredito que o professor, o seu trabalho, serão mais valorizados, que as pessoas passarão a ter um olhar mais humano quanto ao papel desse profissional.

(Diálogo da aluna, 2020).

Suas inquietações, medos e preocupações são em relação ao retorno ao "normal", ao seu filho voltar para escola e não compreender a importância do distanciamento proximal, ou seja, o não contato com os coleguinhas e, nesse processo, seu filho se contaminar e vir a ter alguma complicação de saúde através do contágio com o vírus SARS-CoV-12. Seu medo é a falta de empatia do ser humano com seu próximo, não tendo a capacidade de se colocar no lugar do outro, refletindo que cuidar do outro implica cuidar de si e dos seus. A esperança encontrada em outros relatos de educandos EJA, sensibiliza pela força de luta, pela fé de seguir em frente, pelo desejo de projetar sonhos profissionais e pessoais grandiosos. Que esse relato faça com que reflexões sejam geradas e motivações sejam plantadas, para que se siga acreditando numa sociedade justa e igualitária, concedendo direitos básicos, tais como: educação, saúde, segurança, cultura, lazer e trabalho com qualidade.

\section{Referências}

BRASIL, Lei no 9.394 de 20 de dezembro de 1996. Estabelece as diretrizes e bases da educação nacional. Diário Oficial da União: Seção 1, Brasília, DF. Disponível em: http://www.planalto.gov.br/ccivil_03/LEIS/L9394.htm. Acesso em: 01 set. 2020.

BRASIL, Ministério da Educação. Portaria no 343 de 17 de março de 2020. Dispõe sobre a substituição das aulas presenciais por aulas em meios digitais enquanto durar a situação de pandemia do Novo Coronavírus - COVID-19. Diário Oficial da União: Seção 1, Brasília, DF Disponível em: https://www.normasbrasil.com.br/norma/portaria-343-2020_390743.html. Acesso em: 10 mai. 2020.

D’AMBRÓSIO, Ubiratan. Educação matemática: uma visão do estado da arte. Pró-Posições, Campinas, v. 4, n. 1, p. 7-17, 1993. Disponível em: https://www.fe.unicamp.br/pffe/publicacao/1754/10-artigos-ambrosiou.pdf. Acesso em: 30 out. 2020.

DOWBOR, Fátima Freire. Quem educa marca o corpo do outro. CARVALHO, Sônia Lúcia de. LUPPI, Deise Aparecida. (Orgs.) 2. ed. São Paulo: Cortez, 2008.

FREIRE, Paulo. Pedagogia da indignação: cartas pedagógicas e outros escritos. São Paulo: Unesp, 2000.

GIANCATERINO, Roberto. A matemática sem rituais. Rio de Janeiro: Wak, 2009. 
IBGE, Instituto Brasileiro de Geografia e Estatística. Cidades e estado. 2020. Disponível em: https://www.ibge.gov.br/cidades-e-estados/go/jatai.html. Acesso em: 25 out. 2020.

IDOETA, Paula Adamo. As falhas do ensino da matemática expostas pela pandemia do Coronavírus. BBC News Brasil, São Paulo, 06 jun. 2020. Disponível em: https://www.bbc.com/portuguese/geral52914434. Acesso em: 25 out. 2020.

LIBÂNEO, José Carlos. Didática. São Paulo: Cortez, 1994.

MARIOTTI, Humberto. As paixões do ego. Complexidade, política e solidariedade. São Paulo: Palas Athena, 2000.

MAFFEI, Letícia de Queiroz; SILVA, João Alberto. Um estado da arte sobre os aspectos subjetivos nas pesquisas em educação matemática. Revista Thema, Pelotas, v. 15, n. 2, p. 439-454, 2018. Disponível em: https://periodicos.ifsul.edu.br/index.php/thema/article/view/869/786. Acesso em: 30 out. 2020.

OLIVEIRA, Murilo Alvarenga; CARREIRO, Eduardo de Lima Pinto. O novo normal da educação, quando o virtual não é fictício. Revista Lagos, Rio de Janeiro, v. 11, n. 1, p. 1-3, 2020. Disponível em: https://www.lagos.vr.uff.br/index.php/lagos/article/view/353. Acesso em: 10 ago. 2020.

OLIVEIRA, Terezinha Aparecida de. A utilização da resolução de problemas na modalidade educação de jovens e adultos - eja. Cadernos PDE, Secretaria de Estado da Educação do Paraná, v. 1, 2013. Disponível em:

http://www.gestaoescolar.diaadia.pr.gov.br/modules/conteudo/conteudo.php?conteudo=1631. Acesso em: 25 mai. 2019.

PAMPLONA, Renata Silva; OLIVEIRA, José Sílvio de. O uso panóptico da COVID 19 na educação: sentido, postura! Ligue a câmera, ligue os sentidos, desligue o coração, vamos estudar! Itinerarius Reflectionis, Jataí, v. 16, n. 1, p. 01-19, 2020. Disponível em: https://www.revistas.ufg.br/rir/article/view/65970/35630. Acesso em: 20 nov. 2020.

PRADO, Solange Liége dos Santos. Novo normal na educação. Diário do Aço: Portal de verdade, Ipatinga, 04 nov. 2020. Disponível em: https://mail.diariodoaco.com.br/noticia/0083353-novonormal-na-educacao. Acesso em: 14 nov. 2020.

PRETTO, Nelson De Luca; BONILLA, Maria Helena Silveira; SENA, Ivânia Paula Freitas de Sena (Orgs.).Educação em tempos de pandemia: reflexões sobre as implicações do isolamento físico imposto pela COVID-19. Salvador: Edição do autor, 2020. Disponível em:

https://blog.ufba.br/gec/files/2020/05/GEC_livro_final_imprensa.pdf. Acesso em: 01 jul. 2020.

RIBEIRO, Emerson da Silva. Estado da arte da pesquisa em educação matemática de jovens e adultos: um estudo das teses e dissertações defendidas no Brasil na primeira década do século XXI. Tese (Doutorado em Educação em Ciências e Matemática) - Rede Amazônica de Educação em Ciências e Matemática, Universidade Federal de Mato Grosso, Cuiabá, 2014. Disponível em: https://www1.ufmt.br/ufmt/unidade/userfiles/publicacoes/10a023863a1fbfad1193683fdf28adf9.pd f. Acesso em: 30 out. 2020.

RIBEIRO, Emerson da Silva; DARSIE, Marta Maria Pontin. Estado da arte das teses e dissertações relacionando educação matemática e educação de jovens e adultos: panorama de 10 anos da pesquisa brasileira pós DCNs para a EJA. In: ENCONTRO BRASILEIRO DE ESTUDANTES DE PÓS- 
GRADUAÇÃO EM EDUCAÇÃO MATEMÁTICA, 16. 2012, Canoas. Anais eletrônicos [...]. Canoas: Universidade Luterana do Brasil, 2012. Disponível em: http://www.eventos.ulbra.br/index.php/ebrapem2012/xviebrapem/paper/viewFile/430/293._Acesso em: 30 out. 2020.

RIBEIRO, Emerson da Silva; DARSIE, Marta Maria Pontin. Uma análise das teses em educação matemática de jovens e adultos defendidas no Brasil na primeira década do século XXI. In: ENCONTRO NACIONAL DE EDUCAÇÃO MATEMÁTICA, 12, 2016, São Paulo. Anais eletrônicos [...]. São Paulo: Sociedade Brasileira de Educação Matemática, 2016, p. 01-12. Disponível em: http://www.sbembrasil.org.br/enem2016/anais/pdf/6979_3851_ID.pdf. Acesso em: 30 out. 2020.

SANTOS, Boaventura de Sousa. A cruel pedagogia do vírus. Coimbra-Portugal: Almedina, 2020. Disponível em: https://www.cidadessaudaveis.org.br/cepedoc/wp-content/uploads/2020/04/LivroBoaventura-A-pedagogia-do-virus.pdf. Acesso em: 15 jun. 2020.

SARAIVA, Karla; TRAVERSINI, Clarice; LOCKMANN, Kamila. A educação em tempos de COVID-19: ensino remoto e exaustão docente. Práxis Educativa, Ponta Grossa, v. 15, e2016289, p. 1-24, 2020. Disponível em:

https://revistas2.uepg.br/index.php/praxiseducativa/article/view/16289/209209213529. Acesso em: 25 out. 2020.

SCHIRATO, Maria Aparecida. Novo normal: entenda melhor esse conceito e seu impacto em nossas vidas. Insper, São Paulo, 07 mai. 2020. Disponível em: https://www.insper.edu.br/noticias/novonormal-conceito/. Acesso em: 14 nov. 2020.

SCORTEGAGNA, Paola Andressa; OLIVEIRA, Rita de Cássia da Silva. Educação de jovens e adultos no Brasil: uma análise histórico-crítica. Revista Eletrônica de Ciências da Educação, Campo Largo, v. 5, n. 2, p. 1-15, 2006. Disponível em:

http://www.periodicosibepes.org.br/index.php/reped/article/view/287/193. Acesso em: 05 jul. 2020.

SILVA, Giane Correia; BRANDALISE, Mary Ângela Teixeira. Matemática na educação de jovens e adultos: análise da produção científica do período de 2004-2015. Revista brasileira de Ensino de Ciência e Tecnologia., Ponta Grossa, v. 9, n. 1, p. 202-227, 2016. Disponível em: https://periodicos.utfpr.edu.br/rbect/article/view/3685. Acesso em: 10 mai. 2019.

SOUZA, Bruna Santos de; SILVA, Rodrigo Sychocki. Um relato reflexivo sobre engajamento estudantil e os desafios da prática durante o ensino remoto em 2020. In.: LEIVAS, José Carlos Pinto; BASSO, Marcus Vinicius de Azevedo; SILVA, Rodrigo Sychocki da; SAMÁ, Suzi (Orgs.) Pandemia e educação matemática: relatos e reflexões sobre práticas nas aulas de Matemática durante o Ensino Remoto. Porto Alegre: Mundo Acadêmico, 2021, p. 32-48. Disponível em: https://www.lume.ufrgs.br/handle/10183/223266. Acesso em: 28 ago. 2021. 